\title{
Antibody-conjugated, dual-modal, near-infrared fluorescent iron oxide nanoparticles for antiamyloidgenic activity and specific detection of amyloid- $\beta$ fibrils
}

\author{
This article was published in the following Dove Press journal: \\ International Journal of Nanomedicine \\ 25 October 2013 \\ Number of times this article has been viewed
}

\author{
Hadas Skaat' \\ Enav Corem-Slakmon' \\ Igor Grinberg' \\ David Last ${ }^{2}$ \\ David Goez ${ }^{2}$ \\ Yael Mardor ${ }^{2,3}$ \\ Shlomo Margel' \\ 'Department of Chemistry, Bar-llan \\ Institute of Nanotechnology and \\ Advanced Materials, Ramat-Gan, \\ Israel; ${ }^{2}$ Advanced Technology Center \\ Sheba Medical Center, Tel-Hashomer \\ Ramat-Gan, Israel; ${ }^{3}$ Sackler Faculty \\ of Medicine, Tel-Aviv University, \\ Tel-Aviv, Israel
}

\begin{abstract}
Amyloid- $\beta$ (A $\beta$ ) peptide is the main fibrillar component of plaque deposits found in brains affected by Alzheimer's disease (AD) and is related to the pathogenesis of AD. Passive anti-A $\beta$ immunotherapy has emerged as a promising approach for the therapy of AD, based on the administration of specific anti-A $\beta$ monoclonal antibodies (aA $\beta m A b s)$ to delay $\mathrm{A} \beta$ aggregation in the brain. However, the main disadvantage of this approach is the required readministration of the $\mathrm{aA} \beta \mathrm{mAbs}$ at frequent intervals. There are only a few reports describing in vitro study for the immobilization of aA $\beta \mathrm{mAbs}$ to nanoparticles as potential targeting agents of $A \beta$ aggregates. In this article, we report the immobilization of the aA $\beta \mathrm{mAb}$ clone BAM10 to near-infrared fluorescent maghemite nanoparticles for the inhibition of $A \beta_{40}$ fibrillation kinetics and the specific detection of $\mathrm{A} \beta_{40}$ fibrils. The BAM10-conjugated iron oxide nanoparticles were well-characterized, including their immunogold labeling and cytotoxic effect on PC-12 (pheochromocytoma cell line). Indeed, these antibody-conjugated nanoparticles significantly inhibit the $\mathrm{A} \beta_{40}$ fibrillation kinetics compared with the same concentration, or even five times higher, of the free BAM10. This inhibitory effect was confirmed by different assays such as the photo-induced crosslinking of unmodified proteins combined with sodium dodecyl sulfatepolyacrylamide gel electrophoresis. A cell viability assay also confirmed that these antibodyconjugated nanoparticles significantly reduced the $\mathrm{A} \beta_{40}$-induced cytotoxicity to PC-12 cells. Furthermore, the selective labeling of the $\mathrm{A} \beta_{40}$ fibrils with the BAM10-conjugated near-infrared fluorescent iron oxide nanoparticles enabled specific detection of $A \beta_{40}$ fibrils ex vivo by both magnetic resonance imaging and fluorescence imaging. This study highlights the immobilization of the $a \mathrm{~A} \beta \mathrm{mAb}$ to dual-modal nanoparticles as a potential approach for aA $\beta \mathrm{mAb}$ delivery, eliminating the issue of readministration, and contributes to the development of multifunctional agents for diagnosis and therapy of AD.
\end{abstract}

Keywords: near-infrared fluorescent $\gamma-\mathrm{Fe}_{2} \mathrm{O}_{3}$ nanoparticles, protein folding, amyloid- $\beta$ peptide, passive immunotherapy, neurodegenerative diseases

\section{Introduction}

The formation of amyloid aggregates is associated with the pathogenesis of many neurodegenerative diseases, including Parkinson's, Huntington's, prion, and Alzheimer's disease $(\mathrm{AD}){ }^{1-3}$ The amyloid-related diseases are implicated in the conformational changes of proteins from the normally soluble form into amyloid fibrils, organized mainly into cross $\beta$-sheets. ${ }^{4,5} \mathrm{AD}$ is the most common cause of dementia, characterized by the extracellular deposits of fibrils of a small peptide with 39-43 amino acids, the amyloid- $\beta(\mathrm{A} \beta)$ peptide. ${ }^{6}$ It is generally accepted that the $A \beta$ peptides
Correspondence: Shlomo Margel Department of Chemistry, The Institute of Nanotechnology and Advanced Materials, Bar-llan University,

Max and Anna Web St,

Ramat-Gan 5290002, Israel

$\mathrm{Tel}+972353$ I 886 I

Fax +972 36355208

Email shlomo.margel@mail.biu.ac.il 
can self-assemble to form neurological toxic aggregates with various morphologies, such as soluble oligomers and insoluble protofibrils and fibrils. ${ }^{3,4}$ Recent studies have shown that the soluble $\mathrm{A} \beta$ oligomers are the most toxic species that cause neuritic dystrophy and neuronal death. ${ }^{7-9}$ At this time, amyloid-related diseases are incurable, and treatment options are extremely limited. ${ }^{10,11}$ Inhibition of $A \beta$ aggregation has been considered an attractive therapeutic and preventive strategy for AD treatment. ${ }^{12,13}$

At this time, there is an urgent need for in vivo imaging agents, which are valuable as specific biomarkers to demonstrate the location and density of amyloid plaques in the living human brain. ${ }^{14-16}$ Materials exhibiting fluorescence in the near-infrared (NIR) region (700-1,000 nm) are of great interest as imaging agents, as they result in a lower background signal and deeper tissue penetration. ${ }^{17}$ Among the various NIR fluorescent dyes, NIR cyanine dyes have been used in a wide range of biological and chemical applications. ${ }^{18}$ NIR cyanine dyes are well-known for their water solubility, stability, high sensitivity, and sharp fluorescence bands. ${ }^{18}$ Nanoparticle-based NIR probes have been shown to have significant advantages over free organic NIR dyes such as enhanced photostability and biocompatibility, improved fluorescent signal (a large number of dye molecules per nanoparticle), and easy conjugation of biomolecules to functional groups on the nanoparticle surface. ${ }^{19,20}$

Engineered biocompatible nanoparticles offer advantages as therapeutic and diagnostic agents for amyloid-related diseases, as they allow modification of surface properties and, hence, control over the interaction and adsorption processes. ${ }^{21-25}$ Moreover, in vitro and in vivo studies have shown that nanoparticles are capable of overcoming the difficulty of crossing the blood-brain barrier and have greater in vivo stability. ${ }^{26,27}$ Among the various nanoparticles used in amyloid-related disease research, magnetic iron oxide nanoparticles are particularly promising because of their high biocompatibility, unique magnetic properties, relative nontoxicity, biodegradability, and capacity for use as multimodal contrast agents. ${ }^{28-31}$

The surface areas, compositions, and functionalities of nanoparticles play a significant role in controlling the self-assembling mechanism of amyloid peptides. ${ }^{21-25}$ Only a few studies have been reported on the inhibitory effect of nanoparticles on the $A \beta$ fibrillation process. Very recently, Cabaleiro-Lago et al reported the inhibition of the $A \beta_{40}$ fibril formation by copolymer nanoparticles of variable hydrophobicity ${ }^{32}$ and also demonstrated the dual effect of commercial polystyrene nanoparticles with amino modification toward the $\mathrm{A} \beta_{40}$ and $\mathrm{A} \beta_{42}$ fibril formation. ${ }^{33}$ Yoo et al have shown the inhibition effect of CdTe quantum dots on $\mathrm{A} \beta_{40}$ fibrillation. ${ }^{34}$ Fluorinated nanoparticles, ${ }^{35}$ negatively charged gold nanoparticles, ${ }^{36}$ and sulfonated and sulfated polystyrene nanoparticles also have been reported as potential candidates for the inhibition of $A \beta$ fibril formation. ${ }^{37}$ Our previous studies showed that the Leu-Pro-Phe-Phe-Asp peptide conjugated iron oxide nanoparticles ${ }^{31}$ and the amino acid-based polymer nanoparticles containing hydrophobic dipeptides in the polymer side chains slightly inhibit the $\mathrm{A} \beta_{40}$ fibrillation process. ${ }^{38}$

Passive anti-A $\beta$ immunotherapy has emerged as a promising and effective approach for the treatment of $\mathrm{AD}$ and has already advanced to ongoing clinical trials. ${ }^{39-45}$ This approach involves the direct intraperitoneal injection of anti-A $\beta$ monoclonal antibodies $(\mathrm{aA} \beta \mathrm{mAbs})$ into the body to increase the rate of clearance and prevent aggregation of the $A \beta$ peptide in the brain. ${ }^{39-45}$ Specifically designed aA $\beta m A b s$ have been reported to induce reduction in levels of soluble $\mathrm{A} \beta$ oligomers and plaques, restoration of neuritic architecture, and cognitive function in transgenic mouse models of AD. ${ }^{39,46-49}$ For example, BAM10, a representative aA $\beta \mathrm{mAb}$ recognizing the $N$ terminus of $A \beta$, significantly reduced $A \beta$ plaque burden and reversed memory impairment in different transgenic mouse models of AD. ${ }^{49,50}$ The main disadvantage of passive immunotherapy is the frequent direct injections of the $\mathrm{a} A \beta \mathrm{mAb}$ required to maintain its bioavailability necessary for $A \beta$ clearance from the brain. However, repeated administration may lead to undesirable systematic effects and toxicity as a result of nonspecific distribution and accumulation of the $\mathrm{aA} \beta \mathrm{mAb}$ throughout the body.

Only a few studies have been reported on the immobilization of aA $\beta \mathrm{mAbs}$ on the surface of nanoparticles (ie, gold, ${ }^{51}$ cerium oxide, ${ }^{52}$ magnetite, ${ }^{53}$ and nanoliposomes ${ }^{54}$ ). The purpose of these studies was to increase the in vitro binding affinity of the aA $\beta \mathrm{mAb}$-conjugated nanoparticles to $\mathrm{A} \beta$ oligomers and fibrils as a potential strategy for the diagnosis of AD. Very recently, Sillerud et al reported the use of polyclonal anti-A $\beta$ protein precursor conjugated to iron oxide nanoparticles for in vivo magnetic resonance imaging (MRI) detection of $A \beta$ plaques in the transgenic mouse model of $\mathrm{AD} .{ }^{55}$ However, to the best of our knowledge, there is no report on the immobilization of aA $\beta \mathrm{mAbs}$ on the surface of nanoparticles to control the $\mathrm{A} \beta$ fibrillation process.

The current article describes the newly designed BAM10conjugated NIR fluorescent maghemite $\left(\gamma-\mathrm{Fe}_{2} \mathrm{O}_{3}\right)$ nanoparticles that induce significant inhibition of $\mathrm{A} \beta_{40}$ fibril formation and specific detection of $\mathrm{A} \beta_{40}$ fibrils. These antibody-conjugated 
nanoparticles are well-characterized, including their immunogold labeling and cytotoxic effect on the PC-12 pheochromocytoma cell line. The effect of the immobilization of BAM10 to the fluorescent $\gamma-\mathrm{Fe}_{2} \mathrm{O}_{3}$ nanoparticles on the kinetics of the $A \beta_{40}$ fibrillation process compared with the nonconjugated fluorescent nanoparticles and different concentrations of the free BAM10 is illustrated. The effect of the BAM10-conjugated nanoparticles on the toxicity of the $\mathrm{A} \beta_{40}$ aggregates to $\mathrm{PC}-12$ cells is also examined. The use of the BAM10-conjugated nanoparticles for specific tracing of the $A \beta_{40}$ fibrils in an ex vivo rat brain model by using both MRI and fluorescence imaging is also discussed.

\section{Materials}

The following analytical-grade chemicals were purchased from commercial sources and used without further purification. These include ferrous chloride tetrahydrate; hydrochloric acid (1 M); sodium hydroxide (1 M standard solution); sodium chloride; sodium nitrite; gelatin from porcine skin; human serum albumin (HSA); amyloid- $\beta$ protein fragment 1-40 $\left(\mathrm{A} \beta_{40}\right)$; trifluoroacetic acid (TFA); 1, 1, 1, 3, 3, 3-hexafluoro-2-propanol (HFIP); anhydrous dimethyl sulfoxide (DMSO); thioflavin T (ThT); monoclonal mouse immunoglobulin $\mathrm{G}(\mathrm{IgG})$ anti-A $\beta$ clone BAM10; ammonium persulfate; and tris(2,2'-bipyridyl)dichlororuthenium(II) hexahydrate $\left(\mathrm{RuBpy}_{3}\right)$ from Sigma-Aldrich (St Louis, $\mathrm{MO}$, USA); as well as succinimidyl polyethylene glycol succinimidyl ester (NHS-PEG-NHS) MW 3400 from Nanocs (New York, NY, USA); Cy7-NHS ester from Lumiprobe (Hallandale Beach, FL, USA); mouse IgG enzyme-linked immunosorbent assay (ELISA) kit (Almog Diagnostic Ltd, Shoham, Israel); Midi MACS magnetic columns from Miltenyi Biotec GmbH (Bergisch Gladbach, Germany); Seeblue plus2 prestained standard from Rhenium (Modi'in, Israel); and bicarbonate buffer ( $0.1 \mathrm{M}$ at $\mathrm{pH} 8.4)$, phosphate-buffered saline (PBS free of $\mathrm{Ca}^{+2}$ and $\mathrm{Mg}^{+2}, 0.1 \mathrm{M}$, at $\mathrm{pH}$ 7.4), Roswell Park Memorial Institute medium, fetal calf serum, L-glutamine, penicillin, streptomycin, and 2,3-bis-(2-methoxy-4nitro-5-sulfophenyl)-2H-tetrazolium-5-carboxanilide (XTT) cell viability assay kit from Biological-Industries (Kibbutz Beit-Haemek, Israel). Water was purified by passing deionized water through an Elgastat Spectrum reverse osmosis system (Elga, High Wycombe, UK). The cell line PC-12 was purchased from American Type Culture Collection (ATCC; Manassas, VA, USA). The culture medium used in this study was composed of $90 \%$ Roswell Park Memorial Institute, $10 \%$ fetal calf serum, $2 \mathrm{mM} \mathrm{L}$-glutamine, $50 \mathrm{U} / \mathrm{mL}$ penicillin, and $50 \mu \mathrm{g} / \mathrm{mL}$ streptomycin.

\section{Synthesis of the NIR fluorescent $\gamma-\mathrm{Fe}_{2} \mathrm{O}_{3}$ nanoparticles}

$\mathrm{Cy} 7-\gamma-\mathrm{Fe}_{2} \mathrm{O}_{3}$ nanoparticles $15.0 \pm 1.3 \mathrm{~nm}$ in diameter were prepared by a procedure similar to that described in our previous publication for the preparation of nonfluorescent $\gamma-\mathrm{Fe}_{2} \mathrm{O}_{3}$ nanoparticles ${ }^{56}$ substituting the gelatin for $\mathrm{Cy} 7$-conjugated gelatin. Briefly, Cy7-NHS ester was covalently conjugated to gelatin by adding $0.5 \mathrm{~mL}$ anhydrous DMSO containing $5 \mathrm{mg}$ Cy7-NHS ester to $20 \mathrm{~mL}$ aqueous solution containing $1 \%$ (weight/volume) gelatin at $\mathrm{pH} 8.4$ (the $\mathrm{pH}$ was raised by carefully adding $\mathrm{NaOH}$ aqueous solution $1 \mathrm{~N}$ ). Then the solution was shaken for 1 hour at $60^{\circ} \mathrm{C}$. The volume of the solution was then adjusted to $80 \mathrm{~mL}$ by adding water.

HSA coating onto the $\mathrm{Cy} 7-\gamma-\mathrm{Fe}_{2} \mathrm{O}_{3}$ nanoparticles was performed by the precipitation method, as described in our previous publication. ${ }^{31}$ PEG-derivatized Cy7- $\gamma-\mathrm{Fe}_{2} \mathrm{O}_{3} / \mathrm{HSA}$ nanoparticles were prepared by binding excess NHS-PEGNHS to the HSA coating of the NIR fluorescent iron oxide nanoparticles, according to our previous publication. ${ }^{31}$

\section{Covalent immobilization of the BAMIO to the PEG-derivatized Cy7- $\gamma-\mathrm{Fe}_{2} \mathrm{O}_{3} / \mathrm{HSA}$ nanoparticles}

BAM10 was covalently conjugated to the terminal-activated NHS groups of the PEG-derivatized $\mathrm{Cy} 7-\gamma-\mathrm{Fe}_{2} \mathrm{O}_{3} / \mathrm{HSA}$ core/ shell nanoparticles by adding $50 \mu \mathrm{L}$ of a BAM10 PBS solution $(1 \mathrm{mg} / \mathrm{mL}$ at $\mathrm{pH} 7.4)$ to $1 \mathrm{~mL}$ of the PEG-derivatized Cy7- $\gamma-\mathrm{Fe}_{2} \mathrm{O}_{3} / \mathrm{HSA}$ nanoparticles dispersed in PBS $(2 \mathrm{mg} / \mathrm{mL}$ at $\mathrm{pH}$ 8.4) at a [Nanoparticles]/[BAM10] weight ratio of 40 . The reaction mixture was then shaken at $4{ }^{\circ} \mathrm{C}$ for 20 minutes. Residual NHS groups were then blocked by the addition of glycine ( $1 \%$ weight/volume in PBS). The mixture was then shaken for an additional 30 minutes. The obtained Cy $7-\gamma-$ $\mathrm{Fe}_{2} \mathrm{O}_{3}$ /HSA-PEG-BAM10 nanoparticles were then washed from nonmagnetic waste with PBS, using the hydrophobic grid membrane filter (HGMF) technique. The concentration of the BAM10 conjugated to the fluorescent core/shell maghemite nanoparticles $(7 \pm 0.1 \mu \mathrm{g} / \mathrm{mg}$ nanoparticles $)$ was determined using a mouse IgG ELISA kit (Innovative Research). The reported value is an average of at least three measurements.

\section{BAMIO leakage extent}

The leakage of BAM10, conjugated covalently to the PEGderivatized $\mathrm{Cy} 7-\gamma-\mathrm{Fe}_{2} \mathrm{O}_{3} / \mathrm{HSA}$ nanoparticles, into PBS containing $4 \%$ HSA was evaluated using the following procedure: $\mathrm{Cy} 7-\gamma-\mathrm{Fe}_{2} \mathrm{O}_{3} / \mathrm{HSA}-\mathrm{PEG}-\mathrm{BAM} 10$ nanoparticles 
dispersed in PBS containing 4\% HSA ( $2 \mathrm{mg} / \mathrm{mL}$ at $\mathrm{pH} 7.4$ ) were shaken at room temperature for 24 hours. Then the BAM10-conjugated nanoparticles were removed from the supernatant, using the HGMF technique, and the concentration of BAM10 in the filtrate was measured by the mouse IgG ELISA kit.

\section{Immunogold labeling}

The $\mathrm{Cy} 7-\gamma-\mathrm{Fe}_{2} \mathrm{O}_{3} / \mathrm{HSA}-\mathrm{PEG}-\mathrm{BAM} 10$ nanoparticles were labeled with gold nanoparticles by adding $50 \mu \mathrm{L}$ goat anti-mouse IgG-conjugated gold nanoparticles of $6 \mathrm{~nm}$ (Jackson ImmunoResearch Laboratories, Inc, West Grove, PA, USA) dispersed in $0.01 \mathrm{M}$ sodium borate-sodium phosphate buffer $(1 \mathrm{mg} / \mathrm{mL}$ at $\mathrm{pH} 8.5)$ to $1 \mathrm{~mL}$ of the $\mathrm{Cy} 7-\gamma-\mathrm{Fe}_{2} \mathrm{O}_{3} / \mathrm{HSA}-\mathrm{PEG}-\mathrm{BAM} 10$ nanoparticles dispersed in $\mathrm{PBS}(1 \mathrm{mg} / \mathrm{mL}$ at $\mathrm{pH} 7.4)$. The reaction mixture was then shaken at $4^{\circ} \mathrm{C}$ for 3 hours. The obtained $\mathrm{Cy} 7-\gamma-\mathrm{Fe}_{2} \mathrm{O}_{3} /$ HSA-PEG-BAM10, labeled with gold nanoparticles, was then washed from nonmagnetic waste with PBS, using the HGMF technique. Control experiments were performed similarly, substituting the $\mathrm{Cy} 7-\gamma-\mathrm{Fe}_{2} \mathrm{O}_{3} / \mathrm{HSA}-\mathrm{PEG}-\mathrm{BAM} 10$ nanoparticles for the nonconjugated $\mathrm{Cy} 7-\gamma-\mathrm{Fe}_{2} \mathrm{O}_{3} / \mathrm{HSA}-$ PEG nanoparticles.

\section{Preparation of the $A \beta_{40}$ fibrils in the absence and presence of free BAMI0, BAMI0-conjugated nanoparticles, or nonconjugated nanoparticles}

Lyophilized $\mathrm{A} \beta_{40}$, synthesized by Sigma, was stored at $-20^{\circ} \mathrm{C}$ immediately on arrival. To obtain a homogeneous solution free of aggregates, a variant of Zagorski's protocol ${ }^{57}$ was followed, as discussed in our previous publication. ${ }^{31}$ Briefly, $0.5 \mathrm{mg}$ of the $\mathrm{A} \beta_{40}$ was first dissolved in TFA, followed by TFA evaporation with $\mathrm{N}_{2}$. This process was then repeated another two times. To remove TFA thoroughly, HFIP was added and then evaporated with $\mathrm{N}_{2}$. This HFIP treatment was also repeated another two times. The dry aliquot was completely resuspended in a solution containing 0.5 M DMSO and $0.1 \mathrm{M}$ PBS ( $\mathrm{pH} 7.4$ ), to a final volume of $2.88 \mathrm{~mL}$, to reach a final $A \beta_{40}$ concentration of $40 \mu \mathrm{M}$.

Before use, all solutions were filtered through $0.20-\mu \mathrm{m}-$ pore-size filters. For initiating the $\mathrm{A} \beta_{40}$ fibrillation process, samples of the $A \beta_{40}$ solutions $(40 \mu \mathrm{M})$ were incubated in 1.5-mL Eppendorf tubes in a bath heater at $37^{\circ} \mathrm{C}$ with gentle shaking. To monitor the appearance and growth of fibrils, aliquots from the tubes were taken at different times and added to a black 96-well plate, and the ThT fluorescence
(20 $\mu \mathrm{M}$ ThT added to each well) was measured at $485 \mathrm{~nm}$ with excitation at $435 \mathrm{~nm}$ in a plate reader. ${ }^{58}$

A similar process to that described earlier was also performed in the presence of different concentrations of the nonconjugated or BAM10-conjugated nanoparticles and the free BAM10 (eg, the same concentration as the conjugated one and a concentration five times higher). Briefly, different volumes $\left(0.6-14.5 \mu \mathrm{L}, 2-50 \%\left[\mathrm{w} / \mathrm{w}_{\mathrm{A} \beta 40}\right]\right)$ of an aqueous dispersion of nanoparticles $(3 \mathrm{mg} / \mathrm{mL})$ or $3-15 \mu \mathrm{L}$ of BAM10 PBS solution $(100 \mu \mathrm{g} / \mathrm{mL})$ were added to $0.5 \mathrm{~mL}$ of $40 \mu \mathrm{M}$ $\mathrm{A} \beta_{40}$ PBS solution, as described earlier. The formation of the fibrils was then initiated by quickly raising the temperature of the aqueous mixture from room temperature to $37^{\circ} \mathrm{C}$ for different intervals.

\section{Photo-induced crosslinking of unmodified proteins, followed by tris-tricine-SDS-PAGE}

Photo-induced crosslinking of unmodified proteins (PICUP) was performed according to Bitan's protocol. ${ }^{59}$ Briefly, $18 \mu \mathrm{L}$ of different samples of $\mathrm{A} \beta_{40}(40 \mu \mathrm{M})$, in the absence and presence of $50 \%\left(\mathrm{w} / \mathrm{w}_{\mathrm{A} \beta 40}\right)$ of the BAM10conjugated nanoparticles, were taken at different times in the fibrillation process and added to $0.1-\mathrm{mL}$ Eppendorf tubes. Each tested sample was mixed with $1 \mu \mathrm{L}$ ammonium persulfate (20 mM in $0.1 \mathrm{M}$ PBS solution) and $1 \mu \mathrm{L} \mathrm{RuBpy}_{3}$ (1 $\mathrm{mM}$ in $0.1 \mathrm{M}$ PBS solution). The mixture was then irradiated for 30 seconds, using a 150-W lamp positioned $15 \mathrm{~cm}$ from the bottom of the reaction tube. Then, $10 \mu \mathrm{L}$ of sample buffer containing 5\% $\beta$-mercaptoethanol was immediately added to quench the crosslinking reactions. Each tested sample was separated by electrophoresis at $100 \mathrm{~V}$ for 100 minutes at room temperature by using $16 \%$ tris-tricine-sodium dodecyl sulfate-polyacrylamide gel electrophoresis (SDS-PAGE). ${ }^{59}$ The gels were then developed by the silver stain method. ${ }^{59}$

\section{Cytotoxicity assay}

PC-12 cells were seeded in a 96-well plate at a density of $1 \times 10^{4}$ cells/well in $100 \mu \mathrm{L}$ culture medium and grown in a humidified $5 \% \mathrm{CO}_{2}$ atmosphere at $37^{\circ} \mathrm{C}$. After 18 hours at $37^{\circ} \mathrm{C}, 15 \mu \mathrm{L}$ of preincubated $\mathrm{A} \beta_{40}$ solutions $(40 \mu \mathrm{M})$ in the absence and presence of $10 \%$ or $50 \%\left(\mathrm{w} / \mathrm{w}_{\mathrm{A} \beta 40}\right)$ of the BAM10-conjugated nanoparticles, 70 and 200 hours after the initiation of the fibrillation process, were added to the cells. After incubation for 24 hours at $37^{\circ} \mathrm{C}, 50 \mu \mathrm{L}$ XTT solution was added to each well, according to the kit manufacturer's instructions. Absorbance was read at $480 \mathrm{~nm}$, 
and the absorbance of corresponding concentrations of the nanoparticles was subtracted from the reading. Cell viability was determined as a percentage of the negative control (cultured cells in medium without $\mathrm{A} \beta_{40}$ and nanoparticles).

\section{Ex vivo $M R I$ experiments}

All the experiments were carried out under the Animal Care and Use Committee, which is recognized by the Israeli authorities for animal experimentation. Male naïve Sprague Dawley rats (Harlan, Jerusalem, Israel), aged 2 days, were killed, and their brains were harvested. The extracted brains were fixed in $4 \%$ formalin in a PBS solution for 72 hours at $4{ }^{\circ} \mathrm{C}$ and then washed three times with PBS. The fixed brains were placed in 24-well plate, and $2 \mathrm{~mL}$ of preincubated $\mathrm{A} \beta_{40}(40 \mu \mathrm{M})$ for 70 hours at $37^{\circ} \mathrm{C}$ was added to each well. The brains were then incubated for 24 hours at $37^{\circ} \mathrm{C}$ and washed three times with PBS. Subsequently, $10 \mu \mathrm{L}$ of the BAM10-conjugated nanoparticles $(3 \mathrm{mg} / \mathrm{mL})$ was added to each well, and the brains were incubated at $37^{\circ} \mathrm{C}$ for an additional 24 hours. After incubation, the brains were washed four times with PBS and placed in a six-well plate. A similar control experiment was performed in the presence of the anti-rabbit IgG-conjugated nanoparticles. The anti-rabbit IgG-conjugated nanoparticles were prepared by a similar procedure to that described earlier for the BAM10-conjugated nanoparticles, substituting the BAM10 for the donkey anti-rabbit IgG (Jackson ImmunoResearch Laboratories). Additional control experiments were also performed for rat brains incubated with only $\mathrm{A} \beta_{40}$ or BAM10-conjugated nanoparticles. The treated brains were scanned by MRI, using a 3-T MRI machine (GE Medical Systems, Waukesha, WI, USA) and a clinical phased array knee coil. Fast spin-echo T2-weighted MR images were acquired with a $512 \times 512$ matrix, a field of view of $8 \times 6 \mathrm{~cm}^{2}$, a repetition time of 3,050 milliseconds, an echo time of 82 milliseconds, a bandwidth of $15.63 \mathrm{kHz}$, 4 repetitions, and $1 \mathrm{~mm}$-thick slices.

\section{Statistical analysis}

Statistical analysis was performed by the Student's $t$-test. The results are expressed as a mean \pm standard deviation (SD), and $P<0.05$ was considered to be statistically significant.

\section{Characterization}

Low-resolution transmission electron microscopy (TEM) pictures were obtained with a FEI Tecnai $\mathrm{C} 2$ BioTwin electron microscope (FEI, Hillsboro, OR, USA) with 120-kV accelerating voltage. High-resolution TEM (HRTEM) pictures were obtained by employing a JEOL-2100 (JEOL, Peabody, MA, USA) device with a $200-\mathrm{kV}$ accelerating voltage. Elemental analysis was obtained by the thermo Noran energy dispersive spectroscopy system. Samples for TEM and HRTEM were prepared by placing a drop of diluted sample on a 400-mesh carbon-coated copper grid or carbon-coated copper lacy grid, respectively. The average size and size distribution of the dry nanoparticles were determined by measuring the diameter of more than 200 particles with the image analysis software AnalySIS Auto (Soft Imaging System GmbH, Munster, Germany). Hydrodynamic diameter and size distribution of the nanoparticles dispersed in an aqueous phase were measured using a particle analyzer, model NANOPHOX (Sympatec GmbH, Clausthal-Zellerfeld, Germany). Fluorescence intensity and absorbance at room temperature were measured using a multiplate reader Synergy 4, using Gen 5 software. Electrokinetic properties ( $\zeta$-potential) as a function of $\mathrm{pH}$ were determined by Zetasizer (Zetasizer 2000, Malvern Instruments, Malvern, UK). Fluorescence images were acquired using a Maestro II in vivo fluorescence imaging system (Cambridge Research and Instrumentation Inc, Woburn, MA, USA). A NIR excitation/emission filter set was used for our experiments $\left(\lambda_{\mathrm{ex}}: 700-760 \mathrm{~nm}, \lambda_{\mathrm{em}}>790 \mathrm{~nm}\right)$. The liquid crystal tunable filter was programmed to acquire image cubes from $\lambda=790-860 \mathrm{~nm}$ with an increment of $10 \mathrm{~nm}$ per image.

\section{Results and discussion Characterization of the nonconjugated and the BAMI0-conjugated NIR fluorescent iron oxide nanoparticles}

Uniform NIR fluorescent core $\gamma-\mathrm{Fe}_{2} \mathrm{O}_{3}$ nanoparticles of $15.0 \pm 1.3 \mathrm{~nm}$ were prepared by nucleation followed by the controlled growth of $\gamma-\mathrm{Fe}_{2} \mathrm{O}_{3}$ thin films onto the gelatin-Cy7iron oxide nuclei. ${ }^{31,56}$ These $\mathrm{Cy} 7-\gamma-\mathrm{Fe}_{2} \mathrm{O}_{3}$ nanoparticles were then coated with HSA via a precipitation process. ${ }^{31}$ Covalent conjugation of the spacer arm NHS-PEG-NHS to the HSA coating of the $\mathrm{Cy} 7-\gamma-\mathrm{Fe}_{2} \mathrm{O}_{3}$ nanoparticles was then accomplished by interacting the primary amine groups of the HSA coating with excess NHS-PEG-NHS molecules. Covalent conjugation of the BAM10 onto the surface of the former fluorescent nanoparticles was then performed by interacting the terminal activated NHS groups of the PEG derivatized $\mathrm{Cy} 7-\gamma-\mathrm{Fe}_{2} \mathrm{O}_{3} / \mathrm{HSA}$ nanoparticles with primary amino groups of the antibody. Leakage of the covalently bound BAM10 into PBS containing 4\% HSA was not detected by the mouse IgG ELISA kit. ${ }^{31}$ 


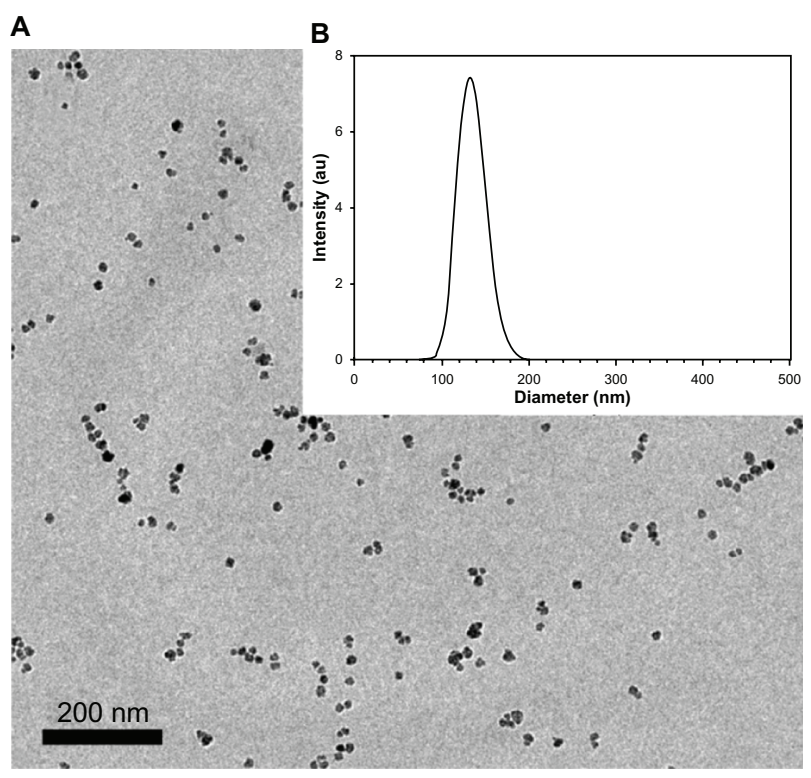

Figure I Transmission electron microscopy image (A) and size histogram (B) of the Cy7-maghemite/human serum albumin-polyethylene glycol-BAMI0 nanoparticles.

Figure 1 presents the dry (A) and hydrodynamic (B) diameter and size distribution of the $\mathrm{Cy} 7-\gamma-\mathrm{Fe}_{2} \mathrm{O}_{3} / \mathrm{HSA}-\mathrm{PEG}-$ BAM10 nanoparticles, as measured by TEM images and light scattering, respectively. The dry diameter is $28 \pm 2.3 \mathrm{~nm}$, whereas the hydrodynamic diameter is $129 \pm 16 \mathrm{~nm}$. The difference in the diameter measured by TEM and light scattering is a result of the fact that the second method also takes into account the surface-adsorbed solvent (water) molecules. The measured dry and hydrodynamic average diameters of the nonconjugated $\mathrm{Cy} 7-\gamma-\mathrm{Fe}_{2} \mathrm{O}_{3} / \mathrm{HSA}-\mathrm{PEG}$ nanoparticles were slightly lower than those of the BAM10-conjugated nanoparticles (eg, $25 \pm 1.9$ and $118 \pm 17 \mathrm{~nm}$, respectively, for the $\mathrm{Cy} 7-\gamma-\mathrm{Fe}_{2} \mathrm{O}_{3} /$ HSA-PEG nanoparticles). Both the nonconjugated and the BAM10-conjugated nanoparticles possess a single population of narrow size distribution, as shown in Figure 1. To learn about the stability of the BAM10-conjugated nanoparticles in aqueous medium, $\zeta$-potential measurements can be employed as an indirect indicator of their surface charge. The $\zeta$-potentials obtained at $\mathrm{pH} 7.4$ for the $\mathrm{Cy} 7-\gamma-\mathrm{Fe}_{2} \mathrm{O}_{3} / \mathrm{HSA}-\mathrm{PEG}$ and $\mathrm{Cy} 7-\gamma-$ $\mathrm{Fe}_{2} \mathrm{O}_{3} / \mathrm{HSA}-\mathrm{PEG}-\mathrm{BAM} 10$ were $-9.5 \pm 2.5$ and $-15.2 \pm 2.7 \mathrm{mV}$, respectively. The increase in the absolute surface charge of the BAM10-conjugated nanoparticles compared with the nonconjugated ones is a strong indication of the effectiveness of the surface modification with BAM10.

HRTEM images of the $\mathrm{Cy} 7-\gamma-\mathrm{Fe}_{2} \mathrm{O}_{3} / \mathrm{HSA}-\mathrm{PEG}$ (Figure 2A) and $\mathrm{Cy} 7-\gamma-\mathrm{Fe}_{2} \mathrm{O}_{3} / \mathrm{HSA}-\mathrm{PEG}-\mathrm{BAM} 10$ (Figure 2B1 and B2) nanoparticles obtained after the immunogold labeling process with the anti-mouse IgG-conjugated gold nanoparticles of $6 \mathrm{~nm}$ are shown in Figure 2. The
HRTEM images of the $\mathrm{Cy} 7-\gamma-\mathrm{Fe}_{2} \mathrm{O}_{3} / \mathrm{HSA}-\mathrm{PEG}$ and Cy7$\gamma$ - $\mathrm{Fe}_{2} \mathrm{O}_{3} / \mathrm{HSA}-\mathrm{PEG}-\mathrm{BAM} 10$ nanoparticles demonstrate the perfect arrangement of the atomic layers of the iron oxide and the amorphous HSA-PEG shell on the surface of the crystalline $\mathrm{Cy} 7-\gamma-\mathrm{Fe}_{2} \mathrm{O}_{3}$ core nanoparticles. The HRTEM images of the $\mathrm{Cy} 7-\gamma-\mathrm{Fe}_{2} \mathrm{O}_{3} / \mathrm{HSA}-\mathrm{PEG}-\mathrm{BAM} 10$ nanoparticles (Figure 2B) also demonstrate the perfect arrangement of the atomic layers of the gold nanoparticle of $6 \mathrm{~nm}$ on the surface of the crystalline $\mathrm{Cy} 7-\gamma-\mathrm{Fe}_{2} \mathrm{O}_{3}$ core nanoparticles. The corresponding energy dispersive spectroscopy spectra reveal the presence of the elemental $\mathrm{Au}$ derived from the Cy7- $\gamma-\mathrm{Fe}_{2} \mathrm{O}_{3} / \mathrm{HSA}-\mathrm{PEG}-\mathrm{BAM} 10$ nanoparticles labeled with the gold nanoparticles (Figure 2D) and its complete absence for the nonlabeled $\mathrm{Cy} 7-\gamma-\mathrm{Fe}_{2} \mathrm{O}_{3} / \mathrm{HSA}-\mathrm{PEG}$ nanoparticles (Figure 2C). These figures clearly exhibit the specific binding of the anti-mouse IgG-conjugated gold nanoparticles to the BAM10-conjugated nanoparticles via antigen-antibody interactions (as illustrated in Figure 2E), which was not observed for the non-BAM10-conjugated nanoparticles. This observation confirms the presence of the immobilized BAM10 molecules on the surface of the Cy7- $\gamma-\mathrm{Fe}_{2} \mathrm{O}_{3} / \mathrm{HSA}-$ PEG-BAM10 nanoparticles.

\section{Influence of the BAMIO immobilization on the kinetics of the $A \beta_{40}$ fibrillation process}

Kinetics of the $\mathrm{A} \beta_{40}$ fibril formation in $\mathrm{PBS}$ at $37^{\circ} \mathrm{C}$, monitored by the temporal development of ThT binding, ${ }^{57}$ in the absence (Figure $3 \mathrm{~A})$ and presence of $50 \%\left(\mathrm{w} / \mathrm{w}_{\mathrm{AB} 40}\right)$ of the nonconjugated (Figure 3B) or BAM10-conjugated nanoparticles (Figure 3C) and free BAM10 of increasing concentrations (Figure 3D and E) are shown in Figure 3. In the absence of the nanoparticles (Figure 3A), the main growth of the $A \beta_{40}$ fibrils, corresponding to the end of the lag time, occurred approximately 60 hours after initiating the fibrillation process and was completed after approximately 120 hours. It is important to note that this behavior was also observed in the presence of $50 \%\left(\mathrm{w} / \mathrm{w}_{\mathrm{A} \beta 40}\right)$ of the non BAM10-conjugated nanoparticles (Figure 3B). In contrast, the kinetics of the $\mathrm{A} \beta_{40}$ fibril growth in the presence of $50 \%\left(\mathrm{w} / \mathrm{w}_{\mathrm{A} \beta 40}\right)$ of the BAM10-conjugated nanoparticles (Figure 3C) was significantly delayed, being initiated only after 340 hours. These observations indicate that the BAM10-conjugated nanoparticles substantially increase the fibrillation lag time and thereby inhibit the kinetics of the nucleation and oligomer formation before the formation of the $A \beta_{40}$ fibrils. This inhibitory effect might be explained by the presence of the surface-immobilized BAM10, which 

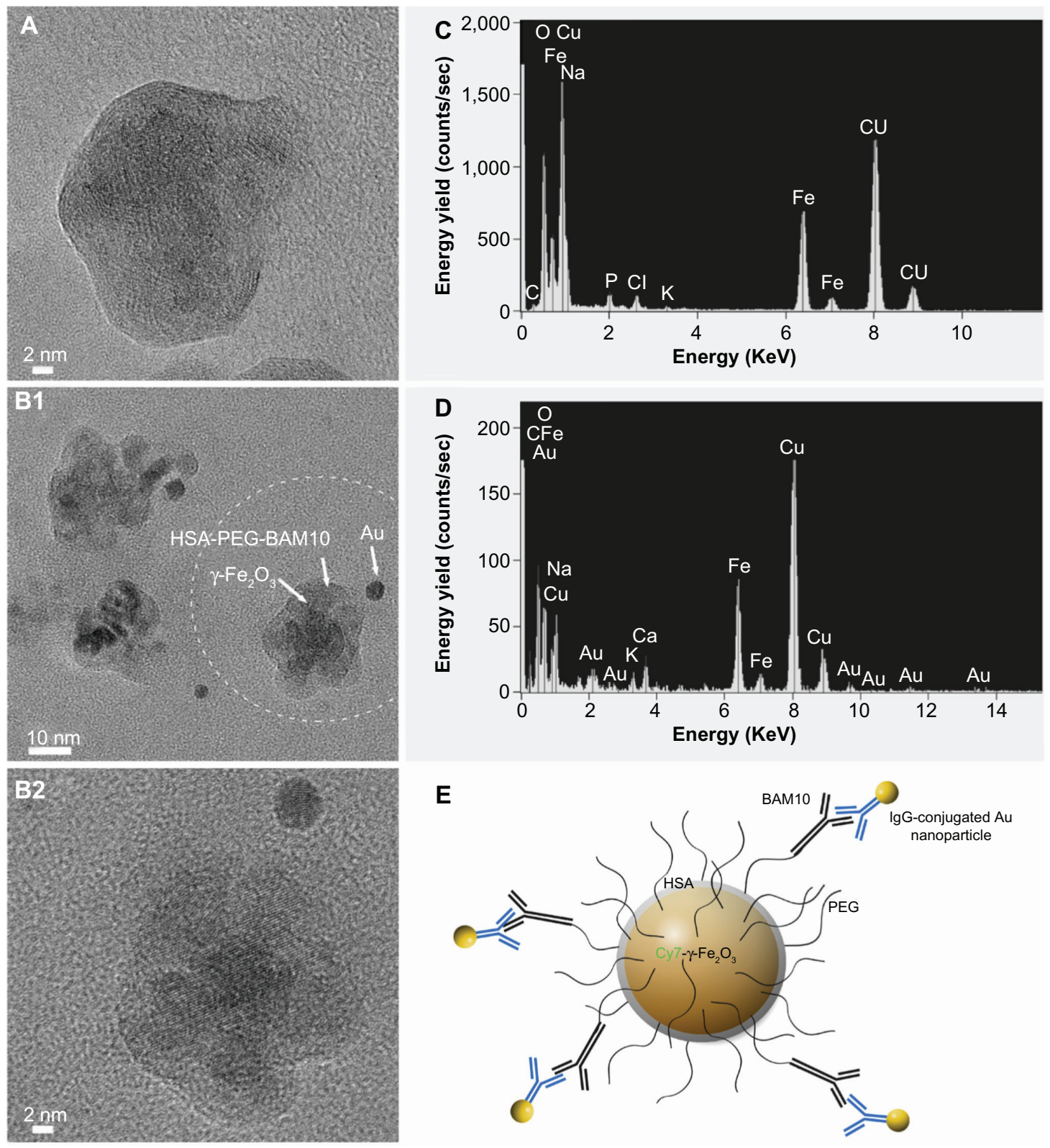

Figure 2 HRTEM images of the Cy7-maghemite/HSA-PEG (A) and Cy7-maghemite/HSA-PEG-BAMI0 nanoparticles (BI and B2) obtained after the immunogold labeling with the anti-mouse lgG-conjugated gold nanoparticles of $6 \mathrm{~nm}$, and their corresponding EDS spectra (C and D, respectively). (E) Scheme illustrating the BAMI0-conjugated nanoparticles labeled with the immunoglobulin G-conjugated gold nanoparticles, as shown in (B2).

Note: Image (B2) represents higher magnification of the circled region shown in (BI).

Abbreviations: HRTEM, high-resolution transmission electron microscopy; HSA, human serum albumin; PEG, polyethylene glycol; EDS, energy dispersive spectroscopy.

is known for its high affinity to $A \beta_{40}$ prefibril aggregates of monomers and oligomers. ${ }^{49,50}$ This high-binding affinity disturbs the monomer-critical nuclei equilibrium by trapping the monomers and/or blocking the growing oligomers ends on the surface of the nanoparticles, thereby decreasing their solution concentration and interfering with their elongation to form fibrils. However, the ability to distinguish whether these nanoparticles adsorbed the monomers or oligomers, or both, remains to be investigated. The effect of the BAM10 immobilization to the nanopar- ticles on the kinetics of $A \beta_{40}$ fibrillation process compared with that with the free antibody at the same concentration $($ free $\times 1)$ and five times higher (free $\times 5$ ) are shown in Figure $3 \mathrm{D}$ and $\mathrm{E}$. These typical sigmoidal curves clearly show that the inhibitory effect observed in the presence of the conjugated BAM10 was substantially higher than that observed for the free $\times 1$, or even free $\times 5$. For example, in the presence of $50 \%\left(\mathrm{w} / \mathrm{w}_{\mathrm{A} \beta 40}\right)$ BAM10-conjugated nanoparticles, the fibrillation process was initiated after 340 hours (Figure 3C), whereas in the presence of the free $\times 1$ (Figure $3 \mathrm{D}$ ) or free $\times 5$ 


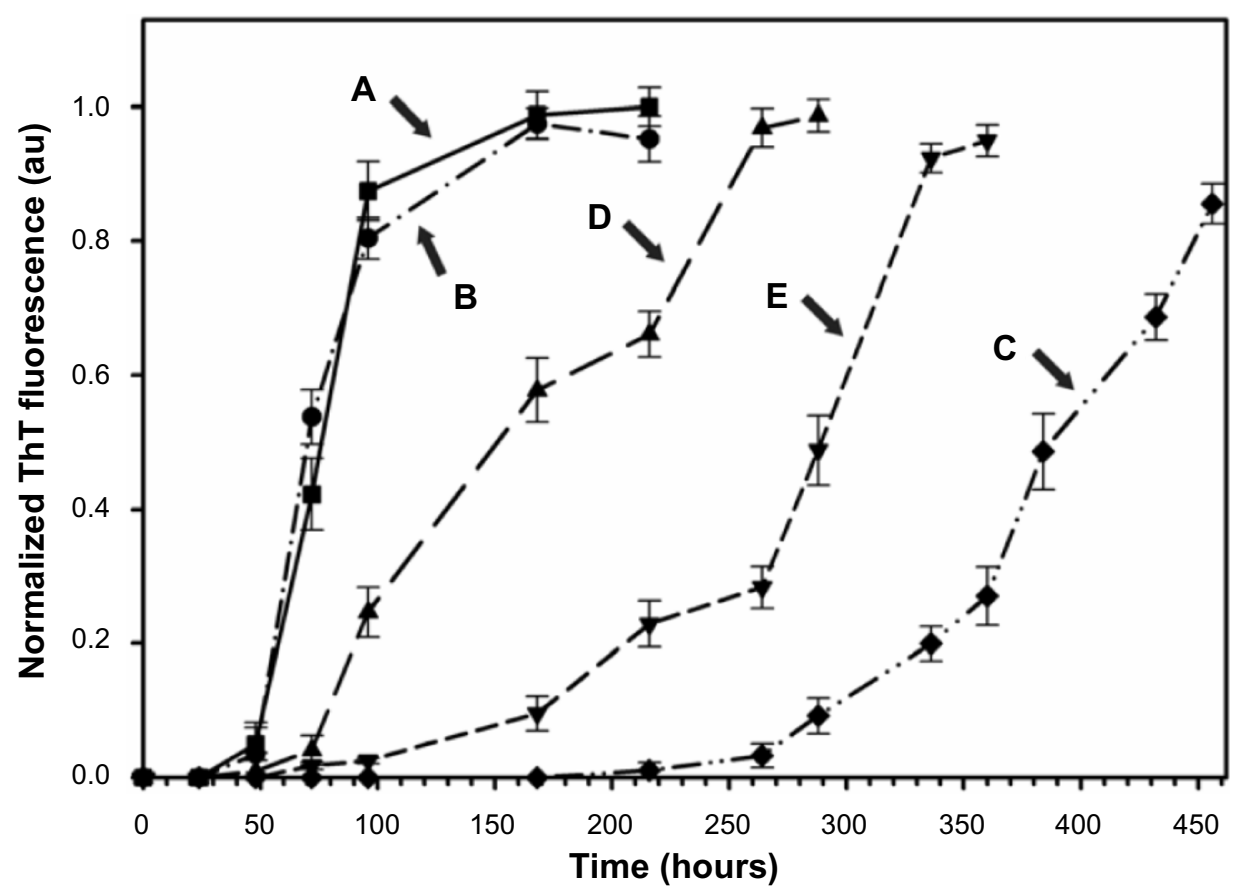

Figure 3 Kinetics of the $A \beta_{40}$ fibrils formation in PBS at $37^{\circ} \mathrm{C}$ in the absence $(\mathbf{A})$ and presence of $50 \%$ ( $w / w_{A \beta 40}$ ) of the nonconjugated (B) or the $B A M I 0-c o n j u g a t e d$ nanoparticles (C) and free BAMIO of different concentrations; that is, the same concentration of the conjugated one (D), and five times higher (E).

Notes: The kinetics of the $A \beta_{40}$ fibrils formation were measured using ThT binding assay, as described in the experimental part. The reported values are the average of five measurements of each triplicate tested sample. The error bars indicate the SD.

Abbreviations: $A \beta_{40}$, amyloid- $\beta$ 40; PBS, phosphate-buffered saline; SD, standard deviation; ThT, thioflavin T.

BAM10 (Figure 3E), the fibrillation process was initiated after 94 and 213 hours, respectively. This observation may be a result of the fact that the immobilization of BAM10 to the nanoparticles increases its stability during the $A \beta_{40}$ fibrillation process, and thus prolongs its activity compared with that of the free antibody. A similar stabilization effect was reported previously by us for thrombin, ${ }^{60} \mathrm{glial}$ cell-derived neurotrophic factor, ${ }^{61}$ basic fibroblast growth factor, ${ }^{62}$ tumor necrosis factor-related apoptosis-inducing ligand (TRAIL), ${ }^{63}$ factor VIIa, ${ }^{64}$ and methotrexate ${ }^{65}$ conjugated to $\gamma-\mathrm{Fe}_{2} \mathrm{O}_{3}$ nanoparticles. Long-term stability of thrombin, TRAIL, and methotrexate conjugated to the $\gamma-\mathrm{Fe}_{2} \mathrm{O}_{3}$ nanoparticles compared with the free ones was also previously demonstrated. ${ }^{60,63,65}$ On the basis of the present in vitro kinetics results, an in vivo study is planned for near future, hopefully to demonstrate the elimination of BAM10 readministration by its conjugation to the iron oxide nanoparticles.

To assess the achieved inhibitory effect on the $\mathrm{A} \beta_{40}$ fibril formation in the presence of the BAM10-conjugated nanoparticles compared with the free $\times 5$ BAM 10 , TEM images were obtained to detect morphological changes in $A \beta_{40}$ solution, as shown in Figure 4 . In the case of control $A \beta_{40}$ solution (Figure 4A), massive networks of entangled fibrils with microsized lengths were observed after 120 hours of the fibrillation process. In contrast, when $\mathrm{A} \beta_{40}$ solution was incubated in the presence of the free $\times 5$ BAM10 (Figure 4B), the formed fibrils after 120 hours of the fibrillation process were less massive and shorter than those observed in the control $A \beta_{40}$ solution. Still, when $A \beta_{40}$ solution was incubated in the presence of $50 \%\left(\mathrm{w} / \mathrm{w}_{\mathrm{A} \beta 40}\right)$ of the BAM10-


Figure 4 TEM images of the $A \beta_{40}$ in the absence $(\mathbf{A})$ and presence $(B)$ of free BAMI0 at a concentration five times higher than the conjugated BAMIO (B) 120 hours after initiation of the fibrillation process or in the presence of $50 \%\left(\mathrm{w} / \mathrm{w}_{A \beta 40}\right)$ of the BAMI0-conjugated nanoparticles dispersed in PBS, 384 (C) and 450 (D) hours after initiation of the fibrillation process.

Abbreviations: TEM, transmission electron microscopy; $A \beta_{40}$, amyloid- $\beta$ 40; PBS, phosphate-buffered saline. 
conjugated nanoparticles (Figure 4C), even shorter fibrils were observed only after 384 hours of the fibrillation process. It is further interesting to note the selective marking of the fibrils with the BAM10-conjugated nanoparticles after 450 hours of the fibrillation process (Figure 4D).

Typical sigmoidal curves in Figure 5 exhibit the kinetics of $A \beta_{40}$ fibrillation process in the presence of increasing concentrations of the BAM10-conjugated nanoparticles (Figure 5A-C). As expected, with increased loading of the BAM10-conjugated nanoparticles, the $A \beta_{40}$ fibrillation process becomes much slower. For example, instead of initiating the fibrillation process in the absence of the nanoparticles after 60 hours, as described earlier, increasing the concentration of the conjugated BAM10 to $2 \%$ (Figure $5 \mathrm{~A}$ ), 10\% (Figure $5 \mathrm{~B}$ ), and $50 \%$ (Figure $5 \mathrm{C})\left(\mathrm{w} / \mathrm{w}_{\mathrm{A} 40}\right)$ leads to fibril formation only after 68,135 , and 340 hours, respectively. It should be noted that at concentrations higher than $50 \%\left(\mathrm{w} / \mathrm{w}_{\mathrm{A} \beta 40}\right)$, no further significant inhibition effect was observed. These results imply that the conjugated BAM10 induces a significant increase in the lag time of the fibrillation process, although it does not prevent the fibril formation. Recent studies have revealed that the soluble oligomers are significantly more toxic to neuronal cells than the monomers and the formed fibrils. ${ }^{7-9}$ Therefore, there is great interest in developing nanoparticles that are able to disturb the monomer-critical nuclei equilibrium by trapping active monomers and prefibril intermediates on the nanoparticle surface, thereby delaying further growth and reducing their toxicity in solution.

To further confirm the achieved inhibitory effect on $\mathrm{A} \beta_{40}$ oligomer distribution during the fibrillation process in the presence of the BAM10-conjugated nanoparticles, the PICUP method, followed by tris-tricine-SDS-PAGE, was performed, as shown in Figure 6. Because the $A \beta_{40}$ oligomers exist under conditions of dynamic equilibrium, the PICUP method was used to stabilize these species by covalent crosslinking and determine their oligomerization state by tris-tricine-SDS-PAGE. In the case of control A $\beta_{40}$ solution, before the initiation of the fibrillation process, the distribution of the PICUP-derived species of $A \beta_{40}$ revealed the presence of a strong monomer band and less intense dimer and trimer bands, indicating the monomers as the species with the highest amount. Following the fibrillation process for 96 hours, the monomer band became less intense, accompanied by the appearance of oligomer bands, indicating the time-dependent decrease in the amount of $A \beta_{40}$ monomers, which aggregated into high-order oligomers and fibrils. In contrast, when $A \beta_{40}$ solution was incubated in the presence of $50 \%\left(\mathrm{w} / \mathrm{w}_{\mathrm{A} \beta 40}\right)$ of the BAM10-conjugated nanoparticles, the monomer band appeared to be strong even after 288 hours of the fibrillation process, indicating that the appearance of the oligomeric species was significantly delayed. These observations indicate that these bioactive-conjugated iron oxide core-shell

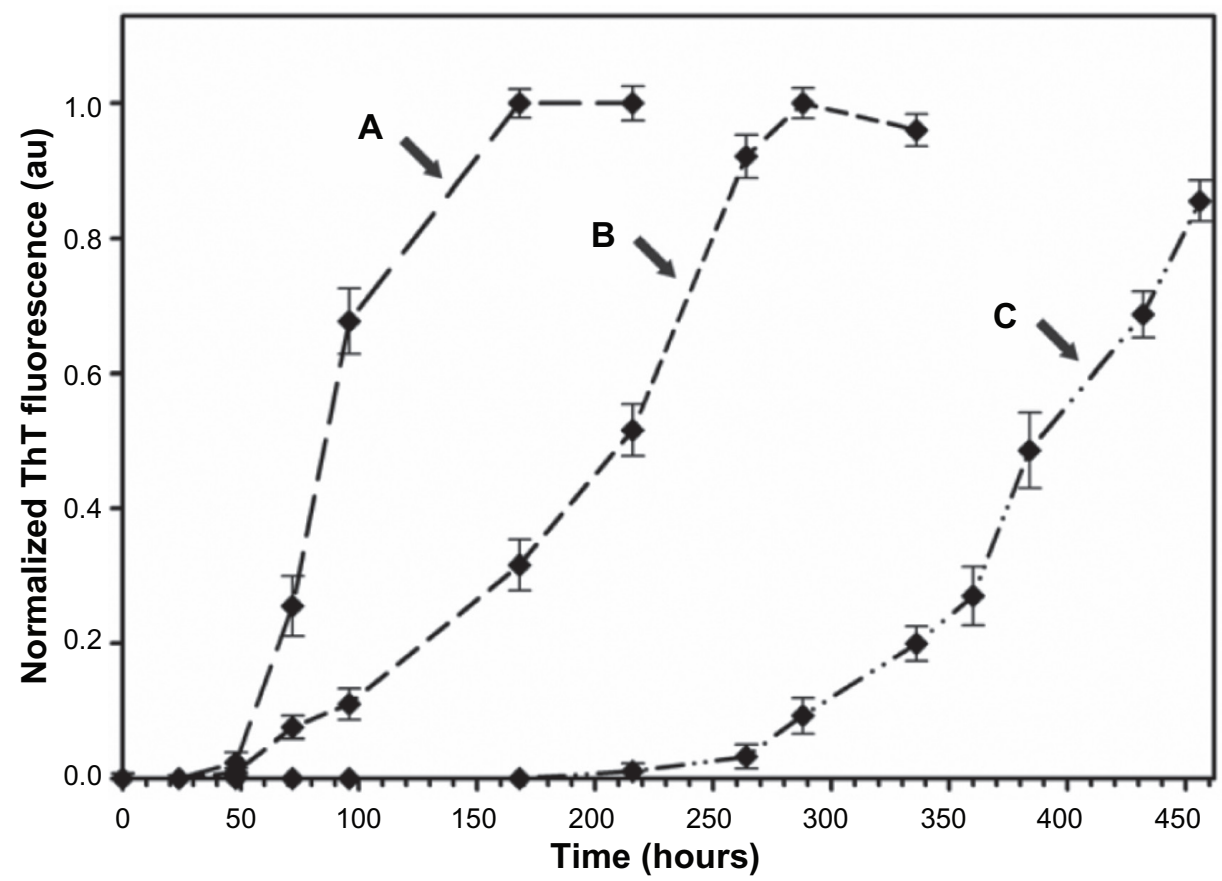

Figure 5 Kinetics of the $A \beta_{40}$ fibrils formation in PBS at $37^{\circ} \mathrm{C}$ in the presence of $2 \%(\mathbf{A}), 10 \%(\mathbf{B})$, and $50 \%(\mathbf{C})\left(\mathrm{w} / \mathrm{w}_{\mathrm{A} \beta 40}\right)$ of the $\mathrm{BAM} / 0$-conjugated nanoparticles. Notes: The kinetics of the $A \beta_{40}$ fibrils formation were measured using ThT binding assay, as described in the experimental part. The reported values are the average of five measurements of each triplicate tested sample. The error bars indicate the SD.

Abbreviations: $A \beta_{40}$, amyloid- $\beta$ 40; PBS, phosphate-buffered saline; ThT, thioflavin T; SD, standard deviation. 


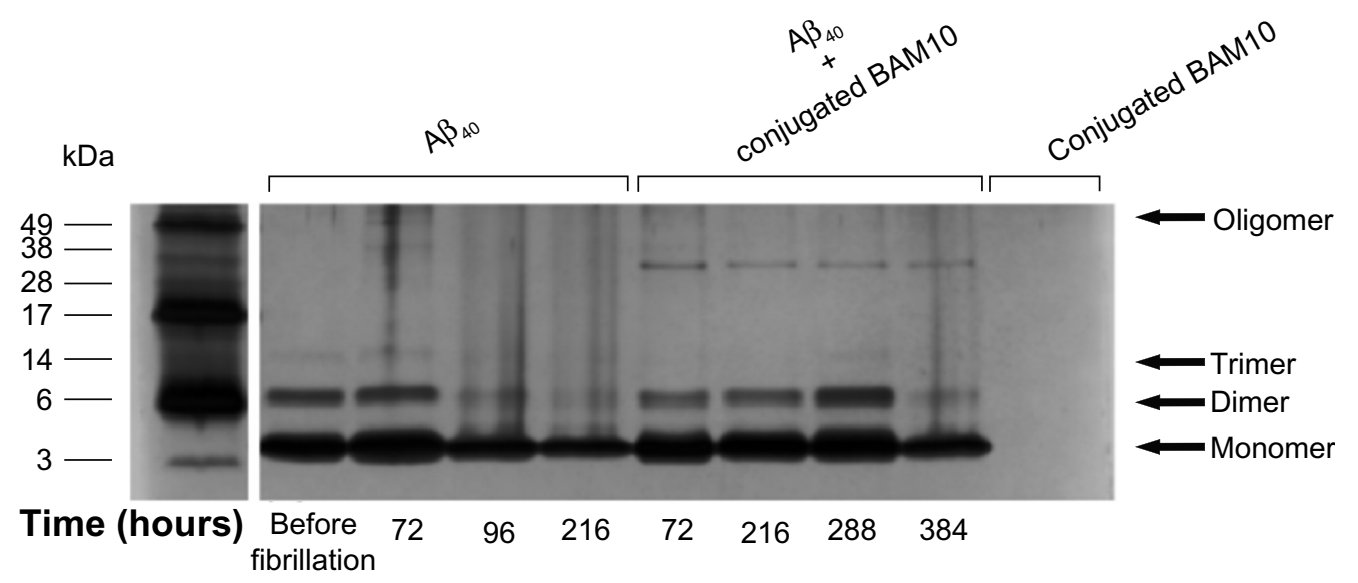

Figure 6 Tris-tricine-SDS-PAGE.

Notes: Tris-tricine-SDS-PAGE illustrating the inhibition effect of the BAMI0-conjugated nanoparticles on the A $\beta_{40}$ fibrillation kinetics. Lanes (from left to right) indicating the electrophoretic migration of the $A \beta_{40}$ in the absence of the nanoparticles before and 72,96 , and 216 hours after the initiation of the fibrillation process; in the presence of the $50 \%\left(\mathrm{w} / \mathrm{w}_{\mathrm{A} \beta 40}\right.$ ) of the BAMI0-conjugated nanoparticles $72,216,288$, and 384 hours after the initiation of the fibrillation process; and of the BAMI0-conjugated nanoparticles only. All tested samples were introduced to PICUP and then were analyzed by $16 \%$ tris-tricine-SDS-PAGE, followed by silver staining, as described in the experimental part. The gel is representative of four independent experiments.

Abbreviations: $A \beta_{40}$, amyloid- $\beta$ 40; PICUP, photo-induced crosslinking of unmodified proteins; SDS-PAGE, sodium dodecyl sulfate-polyacrylamide gel electrophoresis.

nanoparticles are capable of disturbing the monomer-critical nuclei equilibrium by trapping the monomers, thereby delaying their further growth into oligomers.

\section{Effect of the BAMI0-conjugated nanoparticles on the $A \beta_{40}$-induced cytotoxicity}

The effect of the BAM10-conjugated nanoparticles on the toxicity of $\mathrm{A} \beta_{40}$ aggregates to $\mathrm{PC}-12$ cells was examined using XTT cell viability assay, as shown in Figure 7. This figure shows the cell viability percentage after incubation for 24 hours, without and with preincubated fresh $\mathrm{A} \beta_{40}$ aqueous solution in the absence and presence of $10 \%$ or $50 \%\left(\mathrm{w} / \mathrm{w}_{\mathrm{A} \beta 40}\right)$ of the BAM10-conjugated nanoparticles and the presence of free $\times 1$ BAM10, 70 and 200 hours after initiation of the fibrillation process. After a 24 -hour exposure of the $\mathrm{PC}-12$ cells to $\mathrm{A} \beta_{40}$ aggregates formed 70 and 200 hours after initiation of the fibrillation process,

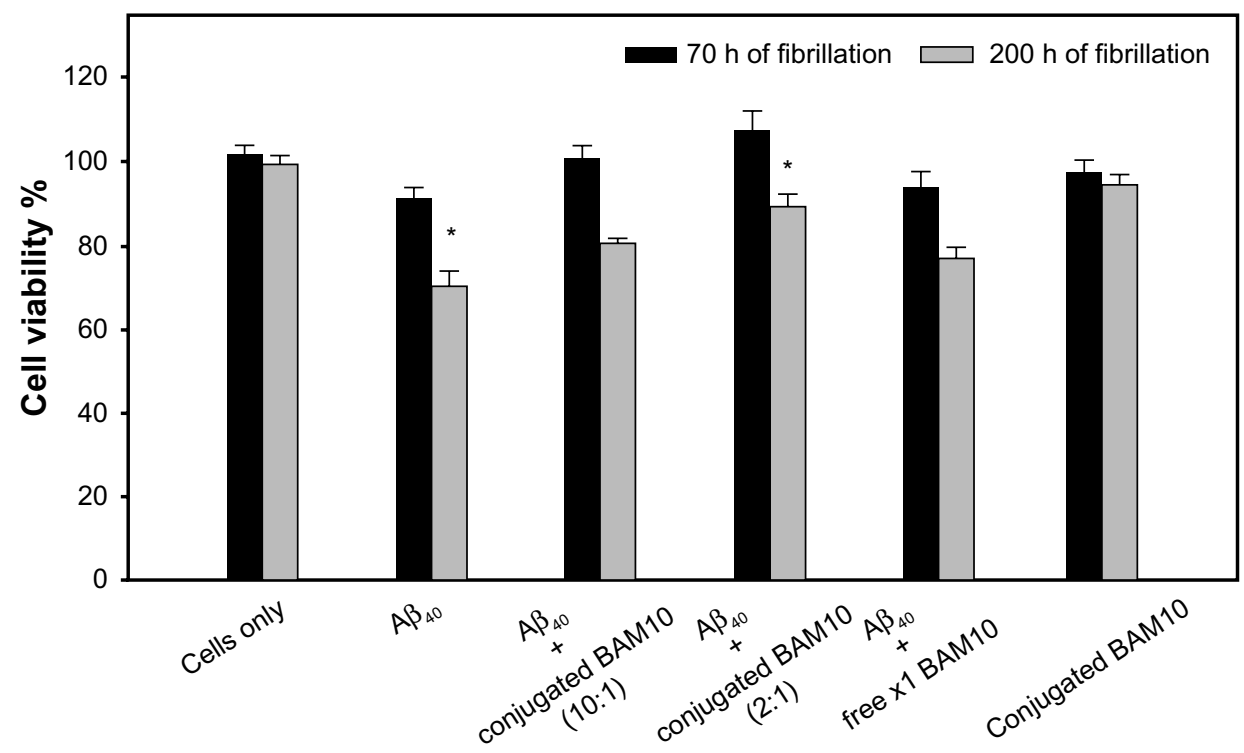

Figure 7 Viability of the PC- 12 cells exposed to preincubated fresh $A \beta_{40}$ aqueous solution in the absence and presence of $10 \%$ or $50 \%\left(w / w_{A B 40}\right.$ ) of the $B A M I 0$-conjugated nanoparticles and presence of the free $\times I$ BAMIO (at the same concentration as the $50 \%\left[\mathrm{w} / \mathrm{w}_{\mathrm{A} \beta 40}\right]$ of the conjugated), 70 and 200 hours after initiation of the fibrillation process, and $50 \%\left(\mathrm{w} / \mathrm{w}_{\mathrm{A} \beta 40}\right)$ of the nanoparticles only under similar conditions, as determined by the XTT assay described in the experimental part.

Notes: The reported values are the average of measurements performed on at least eight wells for each tested sample of two independent experiments, expressed as a percentage of the negative control (cultured cells in medium without $A \beta_{40}$ and nanoparticles). The error bars indicate the standard error of the mean. The statistical analysis was determined using Student's $t$-test. This analysis illustrating significant difference between the $A \beta_{40}$ group to the conjugated $B A M I 0$ group of $50 \%$ ( $\left.w / w_{A \beta 40}\right) * P<0.05$. Abbreviations: $A \beta_{40}$, amyloid- $\beta$ 40; PC-I2, pheochromocytoma cell line; XTT, 2,3-bis-(2-methoxy-4-nitro-5-sulfophenyl)-2H-tetrazolium-5-carboxanilide; h, hours. 


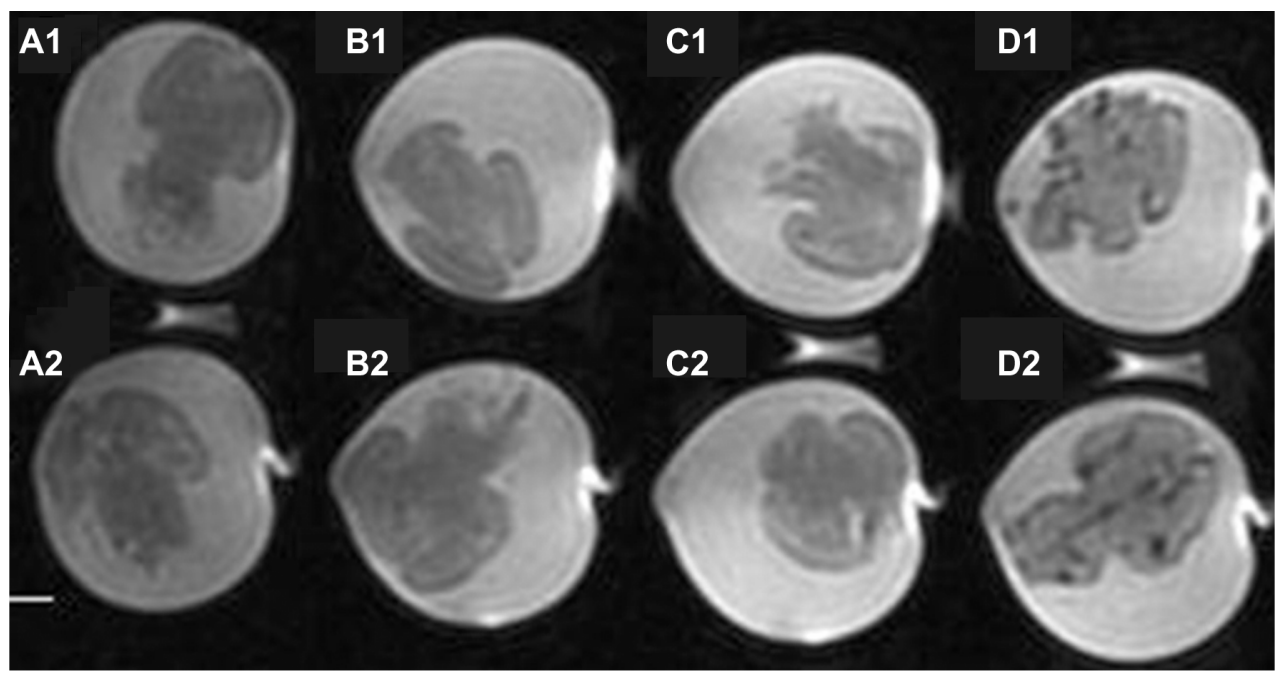

Figure 8 T2-weighted magnetic resonance images of rat brains incubated with $A \beta_{40}$ only (AI and A2), BAMI0-conjugated nanoparticles only (B I and B2), A $\beta_{40}$ followed by anti-rabbit lgG-conjugated nanoparticles (CI and $\mathbf{C 2}$ ), and $A \beta_{40}$ followed by BAMI0-conjugated nanoparticles (DI and D2), as described in the experimental part. Note: This experiment was repeated twice with similar results.

Abbreviations: $A \beta_{40}$, amyloid- $\beta 40$; lgG, immunoglobulin G; MR, magnetic resonance.

the cell viability decreased to $91 \%$ and $71 \%$, respectively. In contrast, after 24 hours of exposure of the PC-12 cells to preincubated $A \beta_{40}$ in the presence of increasing concentrations of the BAM10-conjugated nanoparticles, the cell viability significantly increased in a conjugated BAM10 dose-dependent manner. For example, treatment of the cells with preincubated $A \beta_{40}$ in presence of $50 \%\left(\mathrm{w} / \mathrm{w}_{\mathrm{A} \beta 40}\right)$ of the BAM10-conjugated nanoparticles 200 hours after the initiation of the fibrillation process increased the cell viability from $71 \%$ to $89 \%\left(P<0.05\right.$ between the $\mathrm{A} \beta_{40}$ group to the conjugated BAM10 group of $\left.50 \%\left[\mathrm{w} / \mathrm{w}_{\mathrm{A} \beta 40}\right]\right)$. It should be noted that no toxicity was observed for the nanoparticles tested alone with the cells under similar conditions. These observations indicate that the presence of the BAM10-conjugated nanoparticles during the $A \beta_{40}$ fibrillation process contributed to a significant reduction in neurotoxicity, thereby effectively inhibiting the formation of toxic $\mathrm{A} \beta_{40}$ species.

\section{Ex vivo detection of $A \beta_{40}$ by the dual-modal (MRI and fluorescence) BAMI0-conjugated nanoparticles}

To further test the selective marking of the $\mathrm{A} \beta_{40}$ aggregates with the BAM10-conjugated nanoparticles, ex vivo detection of $\mathrm{A} \beta_{40}$ by these nanoparticles in rat brains was performed. In typical experiments, brains were incubated in a dispersion of $A \beta_{40}$ fibrils to adsorb the fibrils on the surface of the brains. The unbound $A \beta_{40}$ was then removed by thorough washing. The $A \beta_{40}$-adsorbed brains were then treated with functional nanoparticles, followed by removal of the unbound nanoparticles. Figure 8 shows the T2-weighted MR images of the rat brains incubated with only $A \beta_{40}$ (Figure 8A1 and A2) or BAM10-conjugated nanoparticles (Figure 8B1 and B2), and the rat brains incubated with $\mathrm{A} \beta_{40}$, followed by the anti-rabbit IgG-conjugated nanoparticles (Figure $8 \mathrm{C} 1$ and $\mathrm{C} 2$ ) or the BAM10-conjugated nanoparticles (Figure 8D1 and D2). This figure illustrates the presence of dark peripheral outlines of the $A \beta_{40}$-adsorbed brains treated with the BAM10-conjugated nanoparticles (Figure 8D), which does not appear in any of the control
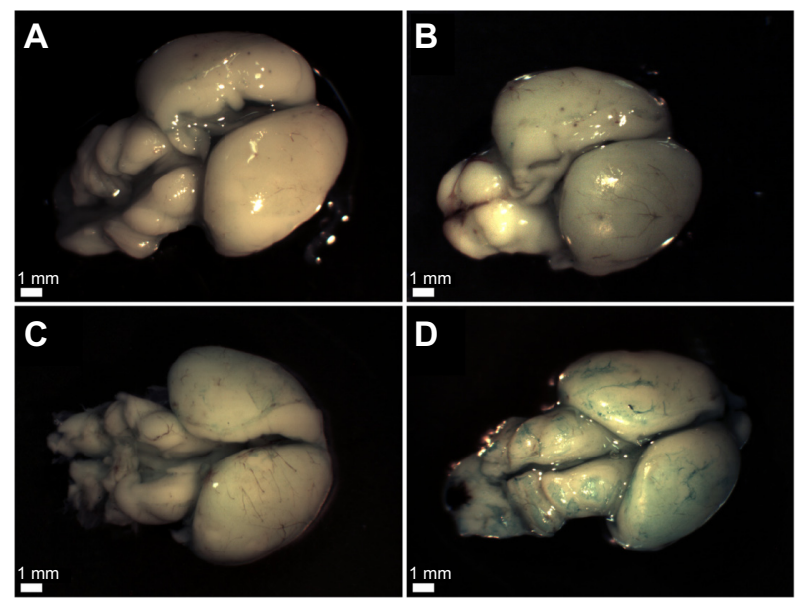

Figure 9 Light microscope images showing the Prussian blue iron staining of the rat brains incubated with: $A \beta_{40}$ only $(\mathbf{A})$, BAMI0-conjugated nanoparticles only (B), $A \beta_{40}$ followed by anti-rabbit IgG-conjugated nanoparticles (C), and $A \beta_{40}$ followed by BAMI0-conjugated nanoparticles (D), as described in the experimental part.

Note: This experiment was repeated three more times with similar results. Abbreviations: $A \beta_{40}$, amyloid- $\beta$ 40; $\lg G$, immunoglobulin $G$. 

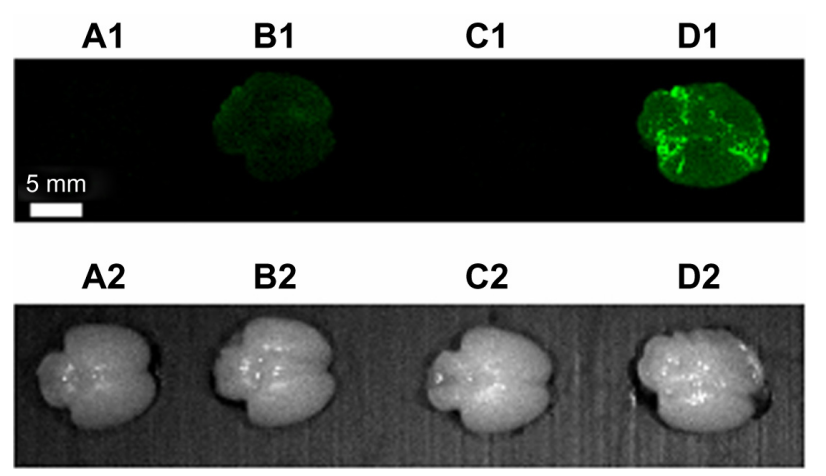

Figure 10 Fluorescence imaging of rat brains incubated with $A \beta_{40}$ only (AI), BAMI0conjugated nanoparticles only (BI), $A \beta_{40}$ followed by anti-rabbit IgG-conjugated nanoparticles $(\mathbf{C I})$, and $A \beta_{40}$ followed by BAMI0-conjugated nanoparticles (DI), as described in the experimental part. (A2-D2) are the corresponding bright light images of the fluorescent images seen in (AI-DI) respectively.

Note: This experiment was repeated three more times with similar results. Abbreviations: $A \beta_{40}$, amyloid- $\beta 40$; lgG, immunoglobulin $G$.

brains (Figure 8A-C). The dark regions in the T2-weighted MR images reflect the existence of iron oxide nanoparticles. These observations indicate the specific binding of the BAM10-conjugated nanoparticles to the $A \beta_{40}$ fibrils in this ex vivo model, without any nonspecific binding with other surface brain components, thus enabling the detection of $A \beta_{40}$ by these nanoparticles, using MRI. The selective tracing of the $A \beta_{40}$ fibrils with the BAM10-conjugated nanoparticles in this ex vivo model was also confirmed by Prussian blue iron staining, as shown in Figure 9. This figure reveals that only the $\mathrm{A} \beta_{40}$-adsorbed brains incubated with the BAM10-conjugated nanoparticles exhibited the characteristic blue color on the surface of the brain as a result of the presence of the iron, in agreement with the MRI results.

Taking advantage of the NIR fluorescent properties of the BAM10-conjugated nanoparticles, fluorescence imaging of the treated brains of the ex vivo experiments described earlier was performed to detect the selective labeling of the $\mathrm{A} \beta_{40}$ fibrils by these bioactive-conjugated nanoparticles, as shown in Figure 10. This figure, indeed, clearly exhibits that only the $A \beta_{40}$-adsorbed brains incubated with the BAM10-conjugated nanoparticles are single-stained with NIR fluorescence belonging to the BAM10-conjugated nanoparticles.

\section{Conclusion}

This article shows that the conjugation of the BAM10 to the NIR fluorescent iron oxide nanoparticles significantly inhibits the $\mathrm{A} \beta_{40}$ fibrillation kinetics and specifically marks these fibrils. The selective labeling of the $A \beta_{40}$ fibrils with the BAM10-conjugated nanoparticles enabled specific detection of $\mathrm{A} \beta_{40}$ fibrils ex vivo by both MRI and fluorescence imaging. These bioactive, dual-modal nanoparticles may therefore be an efficient tool for aA $\beta \mathrm{mAbs}$ delivery and may be used for the development of both therapeutic and diagnostic agents for AD. In the future, we wish to extend this study to transgenic animal models of AD. For this purpose, we plan to study the effect of the conjugated BAM10 compared with the free one on the $\mathrm{A} \beta_{40}$ aggregation of transgenic mice. This will be accomplished, at least at the beginning, by intracranial injections and not intravenously to overcome the blood-brain barrier. We also plan to study the ability of the BAM10-conjugated nanoparticles to specifically detect the $A \beta_{40}$ plaques in the brains of the transgenic animals by tracing the nanoparticles and the $\mathrm{A} \beta_{40}$, using MRI and fluorescence imaging simultaneously, as well as immunohistochemical staining. The cellular uptake of the BAM10-conjugated nanoparticles will also be investigated.

\section{Acknowledgments}

This study was partially supported by a Minerva Grant (Microscale and Nanoscale Particles and Films). The authors also thank Dr Ilana Perelshtein and Dr Judith Grinblat (BarIlan University, Israel) for their help in obtaining the HRTEM images.

\section{Disclosure}

The authors report no conflicts of interest in this work.

\section{References}

1. Jellinger KA. Interaction between pathogenic proteins in neurodegenerative disorders. J Cell Mol Med. 2012;16(6):1166-1183.

2. Moreno-Gonzalez I, Soto C. Misfolded protein aggregates: mechanisms, structures and potential for disease transmission. Semin Cell Dev Biol. 2011;22(5):482-487.

3. Chiti F, Dobson CM. Protein misfolding, functional amyloid, and human disease. Annu Rev Biochem. 2007;5:333-366

4. Kumar S, Udgaonkar JB. Mechanisms of amyloid fibril formation by proteins. Curr Sci. 2010;98:639-656.

5. Marshall KE, Serpell LC. Insights into the structure of amyloid fibrils. Open Biol J. 2009;2:185-192.

6. Roychaudhuri R, Yang M, Hoshi MM, Teplow DB. Amyloid betaprotein assembly and Alzheimer disease. J Biol Chem. 2009;284(8): 4749-4753.

7. Haass C, Selkoe DJ. Soluble protein oligomers in neurodegeneration: lessons from the Alzheimer's amyloid beta-peptide. Nat Rev Mol Cell Biol. 2007;8(2):101-112.

8. Sakono M, Zako T. Amyloid oligomers: formation and toxicity of Abeta oligomers. FEBS J. 2010;277(6):1348-1358.

9. Ferreira ST, Vieira MN, De Felice FG. Soluble protein oligomers as emerging toxins in Alzheimer's and other amyloid diseases. IUBMB Life. 2007;59(4-5):332-345.

10. Sheikh S, Safia, Haque E, Mir SS. Neurodegenerative diseases: multifactorial conformational diseases and their therapeutic interventions. J Neurodegener Dis. 2013; article ID 563481. 
11. Yiannopoulou KG, Papageorgiou SG. Current and future treatments for Alzheimer's disease. Ther Adv Neurol Disord. 2013;6(1):19-33.

12. Härd T, Lendel C Inhibition of amyloid formation. $J$ Mol Biol. 2012;421(4-5):441-465.

13. Liu R, Su R, Liang M, et al. Physicochemical strategies for inhibition of amyloid fibril formation: an overview of recent advances. Curr Med Chem. 2011;9(24):4157-4174.

14. Mathis CA, Mason NS, Lopresti BJ, Klunk WE. Development of positron emission tomography $\beta$-amyloid plaque imaging agents. Semin Nucl Med. 2012;42(6):423-432.

15. Ono M, Saji H. SPECT Imaging Agents for Detecting Cerebral B-Amyloid Plaques. Int J Mol Imaging. 2011;2011:543267.

16. Wong DF, Rosenberg PB, Zhou Y, et al. In vivo imaging of amyloid deposition in Alzheimer disease using the radioligand 18F-AV-45 (florbetapir [corrected] F 18). J Nucl Med. 2010;51(6):913-920.

17. Schmidt A, Pahnke J. Efficient near-infrared in vivo imaging of amyoid- $\beta$ deposits in Alzheimer's disease mouse models. J Alzheimers Dis. 2013;0(3):651-664.

18. Quek CH, Leong KW. Near-infrared fluorescent nanoprobes for in vivo optical imaging. Nanomaterials. 2012;2:92-112.

19. He X, Wang K, Cheng Z. In vivo near-infrared fluorescence imaging of cancer with nanoparticle-based probes. Wiley Interdiscip Rev Nanomed Nanobiotechnol. 2010;2(4):349-366.

20. Wu X, Chang S, Sun X, et al. Constructing NIR silica-cyanine hybrid nanocomposite for bioimaging in vivo: a breakthrough in photo-stability and bright fluorescence with large Stokes shift. Chem Sci. 2013;4: 1221-1228.

21. Mahmoudi M, Kalhor HR, Laurent S, Lynch I. Protein fibrillation and nanoparticle interactions: opportunities and challenges. Nanoscale. 2013;5(7):2570-2588.

22. Spuch C, Saida O, Navarro C. Advances in the treatment of neurodegenerative disorders employing nanoparticles. Recent Pat Drug Deliv Formul. 2012;6(1):2-18.

23. Re F, Gregori M, Masserini M. Nanotechnology for neurodegenerative disorders. Maturitas. 2012;73(1):45-51.

24. Sahni JK, Doggui S, Ali J, Baboota S, Dao L, Ramassamy C. Neurotherapeutic applications of nanoparticles in Alzheimer's disease. $J$ Control Release. 2011;152(2):208-231.

25. Cabaleiro-Lago C, Szczepankiewicz O, Linse S. The effect of nanoparticles on amyloid aggregation depends on the protein stability and intrinsic aggregation rate. Langmuir. 2012;28(3):1852-1857.

26. Silva GA. Neuroscience nanotechnology: progress, opportunities and challenges. Nat Rev Neurosci. 2006;7(1):65-74.

27. Kabanov AV, Gendelman HE. Nanomedicine in the diagnosis and therapy of neurodegenerative disorders. Prog Polym Sci. 2007;32(8-9): 1054-1082.

28. Wadghiri YZ, Li J, Wang J, et al. Detection of amyloid plaques targeted by bifunctional USPIO in Alzheimer's disease transgenic mice using magnetic resonance microimaging. PLoS One. 2018(2):e57097.

29. Mahmoudi M, Quinlan-Pluck F, Monopoli MP, et al. Influence of the physiochemical properties of superparamagnetic iron oxide nanoparticles on amyloid $\beta$ protein fibrillation in solution. ACS Chem Neurosci. 2013;4(3):475-485.

30. Kouyoumdjian H, Zhu DC, El-Dakdouki MH, et al. Glyconanoparticle aided detection of $\beta$-amyloid by magnetic resonance imaging and attenuation of $\beta$-amyloid induced cytotoxicity. ACS Chem Neurosci. 2013;4(4):575-584.

31. Skaat H, Shafir G, Margel S. Acceleration and inhibition of amyloid- $\beta$ fibril formation by peptide-conjugated fluorescent-maghemite nanoparticles. J Nanopart Res. 2011;13:3521-3534.

32. Cabaleiro-Lago C, Quinlan-Pluck F, Lynch I, et al. Inhibition of amyloid beta protein fibrillation by polymeric nanoparticles. $\mathrm{J} \mathrm{Am} \mathrm{Chem} \mathrm{Soc.}$ 2008;130(46):15437-15443.

33. Cabaleiro-Lago C, Quinlan-Pluck F, Lynch I, Dawson KA, Linse S. Dual effect of amino modified polystyrene nanoparticles on amyloid $\beta$ protein fibrillation. ACS Chem Neurosci. 2010;1(4): 279-287.
34. Yoo SI, Yang M, Brender JR, et al. Inhibition of amyloid peptide fibrillation by inorganic nanoparticles: functional similarities with proteins. Angew Chem Int Ed Engl. 2011;50(22):5110-5115.

35. Saraiva AM, Cardoso I, Pereira MC, et al. Controlling amyloid-beta peptide(1-42) oligomerization and toxicity by fluorinated nanoparticles. Chembiochem. 2010;11(13):1905-1913.

36. Liao YH, Chang YJ, Yoshiike Y, Chang YC, Chen YR. Negatively charged gold nanoparticles inhibit Alzheimer's amyloid- $\beta$ fibrillization, induce fibril dissociation, and mitigate neurotoxicity. Small. 2012;8(23): 3631-3639.

37. Saraiva AM, Cardoso I, Saraiva MJ, et al. Randomization of amyloid$\beta$-peptide(1-42) conformation by sulfonated and sulfated nanoparticles reduces aggregation and cytotoxicity. Macromol Biosci. 2010;10(10): $1152-1163$.

38. Skaat H, Chen R, Grinberg I, Margel S. Engineered polymer nanoparticles containing hydrophobic dipeptide for inhibition of amyloid- $\beta$ fibrillation. Biomacromolecules. 2012;13(9):2662-2670.

39. Moreth J, Mavoungou C, Schindowski K. Passive anti-amyloid immunotherapy in Alzheimer's disease: What are the most promising targets? Immun Ageing. 2013;10(1):18.

40. Yu YJ, Watts RJ. Developing therapeutic antibodies for neurodegenerative disease. Neurotherapeutics. 2013;10(3):459-472.

41. Lobello K, Ryan JM, Liu E, Rippon G, Black R. Targeting Beta amyloid: a clinical review of immunotherapeutic approaches in Alzheimer's disease. Int J Alzheimers Dis. 2012;2012:628070.

42. Aisen PS, Vellas B. Passive immunotherapy for Alzheimer's disease: what have we learned, and where are we headed? J Nutr Health Aging. 2013;17(1):49-50.

43. Fu HJ, Liu B, Frost JL, Lemere CA. Amyloid-beta immunotherapy for Alzheimer's disease. CNS Neurol Disord Drug Targets. 2010;9(2): 197-206.

44. Wilcock DM, Colton CA. Anti-amyloid-beta immunotherapy in Alzheimer's disease: relevance of transgenic mouse studies to clinical trials. J Alzheimers Dis. 2008;15(4):555-569.

45. Schenk D, Hagen M, Seubert P. Current progress in beta-amyloid immunotherapy. Curr Opin Immunol. 2004;16(5):599-606.

46. Yamada K, Yabuki C, Seubert P, et al. Abeta immunotherapy: intracerebral sequestration of Abeta by an anti-Abeta monoclonal antibody 266 with high affinity to soluble Abeta. J Neurosci. 2009;29(36):11393-11398.

47. Wilcock DM, DiCarlo G, Henderson D, et al. Intracranially administered anti-Abeta antibodies reduce beta-amyloid deposition by mechanisms both independent of and associated with microglial activation. J Neurosci. 2003;23(9):3745-3751.

48. Spires-Jones TL, Mielke ML, Rozkalne A, et al. Passive immunotherapy rapidly increases structural plasticity in a mouse model of Alzheimer disease. Neurobiol Dis. 2009;33(2):213-220.

49. Kotilinek LA, Bacskai B, Westerman M, et al. Reversible memory loss in a mouse transgenic model of Alzheimer's disease. J Neurosci. 2002;22(15):6331-6335.

50. Jordão JF, Ayala-Grosso CA, Markham K, et al. Antibodies targeted to the brain with image-guided focused ultrasound reduces amyloid-beta plaque load in the TgCRND8 mouse model of Alzheimer's disease. PLoS One. 11, 2010;5(5):e10549.

51. Sakono M, Zako T, Maeda M. Naked-eye detection of amyloid aggregates using gold nanoparticles modified with amyloid beta antibody. Anal Sci. 2012;28(1):73.

52. Cimini A, D'Angelo B, Das S, et al. Antibody-conjugated PEGylated cerium oxide nanoparticles for specific targeting of $A \beta$ aggregates modulate neuronal survival pathways. Acta Biomater. 2012;8(6): 2056-2067.

53. Yang CC, Yang SY, Chieh JJ, et al. Biofunctionalized magnetic nanoparticles for specifically detecting biomarkers of Alzheimer's disease in vitro. ACS Chem Neurosci. 2011;2(9):500-505.

54. Canovi M, Markoutsa E, Lazar AN, et al. The binding affinity of anti$\mathrm{A} \beta 1-42 \mathrm{MAb}$-decorated nanoliposomes to $\mathrm{A} \beta 1-42$ peptides in vitro and to amyloid deposits in post-mortem tissue. Biomaterials. 2011;32(23): 5489-5497. 
55. Sillerud LO, Solberg NO, Chamberlain R, et al. SPION-enhanced magnetic resonance imaging of Alzheimer's disease plaques in $\mathrm{A} \beta \mathrm{PP} /$ PS-1 transgenic mouse brain. J Alzheimers Dis. 2013;34(2):349-365.

56. Sigalit Gura, Shlomo Margel, inventors; Bar-Ilan University, assignee. Nucleation and growth of magnetic metaloxide nanoparticles and its use. Israel patent WO 1999062079A1. May 24, 1999.

57. Chen S, Wetzel R. Solubilization and disaggregation of polyglutamine peptides. Protein Sci. 2001;10(4):887-891.

58. Levine $\mathrm{H}$. Thioflavine $\mathrm{T}$ interaction with amyloid $\beta$-sheet structures. Amyloid. 1995;2:1-6.

59. Bitan G, Lomakin A, Teplow DB. Amyloid beta-protein oligomerization: prenucleation interactions revealed by photo-induced cross-linking of unmodified proteins. J Biol Chem. 2001;276(37):35176-35184.

60. Ziv-Polat O, Topaz M, Brosh T, Margel S. Enhancement of incisional wound healing by thrombin conjugated iron oxide nanoparticles. Biomaterials. 2010;31(4):741-747.

61. Green-Sadan T, Kuttner Y, Lublin-Tennenbaum T, et al. Glial cell linederived neurotrophic factor-conjugated nanoparticles suppress acquisition of cocaine self-administration in rats. Exp Neurol. 2005;194(1): 97-105.
62. Skaat H, Ziv-Polat O, Shahar A, Margel S. Enhancement of the growth and differentiation of nasal olfactory mucosa cells by the conjugation of growth factors to functional nanoparticles. Bioconjug Chem. 2011;22(12):2600-2610.

63. Shlomo Margel, Benny Perlstein, Chaya Brodie, tom Mikkelsen, inventors; Bar-Ilan University, assignee. Polymer nanoparticles coated by magnetic metal oxide and uses thereof. US patent WO 2009/040811. April 2, 2009

64. Shafir G, Galperin A, Margel S. Synthesis and characterization of recombinant factor VIIa-conjugated magnetic iron oxide nanoparticles for hemophilia treatment. J Biomed Mater Res A. 2009;91(4): 1056-1064.

65. Corem-Salkmon E, Ram Z, Daniels D, et al. Convection-enhanced delivery of methotrexate-loaded maghemite nanoparticles. Int $J$ Nanomedicine. 2011;6:1595-1602.
International Journal of Nanomedicine

\section{Publish your work in this journal}

The International Journal of Nanomedicine is an international, peerreviewed journal focusing on the application of nanotechnology in diagnostics, therapeutics, and drug delivery systems throughout the biomedical field. This journal is indexed on PubMed Central, MedLine, CAS, SciSearch ${ }^{\circledR}$, Current Contents ${ }^{\circledR} /$ Clinical Medicine,

\section{Dovepress}

Journal Citation Reports/Science Edition, EMBase, Scopus and the Elsevier Bibliographic databases. The manuscript management system is completely online and includes a very quick and fair peer-review system, which is all easy to use. Visit http://www.dovepress.com/ testimonials.php to read real quotes from published authors. 